\title{
A syndrome of hypotonia, psychomotor retardation, seizures, delayed and dysharmonic skeletal maturation, and congenital fibre type disproportion
}

\author{
Qutub H Qazi, Demetrios Markouizos, Chandrakant Rao, Tariq Sheikh, \\ Eva Beller, Roger Kula
}

\begin{abstract}
Three unrelated Puerto Rican boys, ranging in age from 3 to 4 years, had marked, central, non-progressive hypotonia, chronic constipation, severe psychomotor retardation, seizures or abnormal electroencephalograph or both, abnormal dermatoglyphics, delayed bone age, dysharmonic skeletal maturation, and preponderance and larger size of type 2 muscle fibres. Additional findings included narrow, high arched palate, prominent nasal root, long philtrum, distended abdomen, and drooling from open mouth. Two of the three patients also had undescended testes, hypertelorism, and tapered fingers. Birth weight, postnatal physical growth, and head size were average. Family and gestational histories and laboratory evaluations were normal. The combination of features observed in the three boys appears to be distinct and to represent a new syndrome.
\end{abstract}

( $\mathcal{F}$ Med Genet 1994;31:405-409)

The list of known conditions associated with congenital hypotonia and developmental retardation is extensive and includes clinically and aetiologically disparate disorders. ${ }^{1}$ This report is about three unrelated boys who had a unique, hitherto undescribed combination of congenital non-progressive hypotonia and severe mental retardation with neurological, gastrointestinal, and skeletal abnormalities.

\section{Case reports}

CASE 1

This patient was delivered at term by caesarean section because of an abnormal lie. Birth weight was $3150 \mathrm{~g}$. Severe hypotonia was noted at birth and the patient needed respiratory assistance. For a brief period thereafter he had problems of sucking and swallowing. Milestones were markedly delayed; he smiled at 6 months, and at the age of 1 year he started making efforts to turn to the side and reach for objects. Chronic constipation necessitated frequent use of suppositories and recurrent chest infections were treated in hospitals in Puerto Rico.
At the age of 4 years he weighed $19.8 \mathrm{~kg}$ (90th centile), was $98 \mathrm{~cm}$ in length (20th centile), and had a head circumference (OFC) of $41 \mathrm{~cm}$ (50th centile). He lay in a frog leg position, was alert and conscious, but had a poor grasp and feeble cry. He was unable to sit, stand, crawl, or creep. The fontanelles were closed and the occiput was flat. The ears were normal in length $(5 \mathrm{~cm})$ and the nasal root was prominent (fig 1). The mouth remained open, the gag reflex was weak, and there was no evidence of fasciculations or atrophy of the tongue. His philtrum was long, the teeth hypoplastic, and the palate narrow and highly arched. He showed hypertelorism; interpupillary distance (IPD) was $6 \mathrm{~cm}$. He had concomitant convergent strabismus bilaterally; the funduscopic examination did not show any abnormality. A moderately severe pectus excavatum was present and the lower ribs showed flaring. The heart and lungs were normal. The abdomen appeared distended and the liver edge was palpable $1 \mathrm{~cm}$ below the right costal margin. The penis was normal and the scrotum was hypoplastic and empty. Muscle weakness was severe and generalised. All deep tendon reflexes were absent and plantars were decreased bilaterally. Moro, parachute, and tonic neck reflexes were negative. The spine and patellae appeared normal and the fingers were tapered.

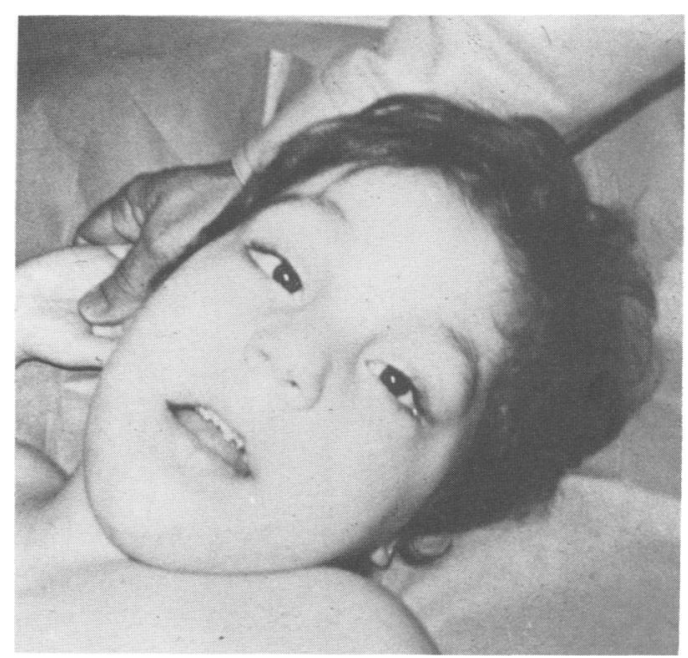

Figure 1 Case 1: strabismus, broad nasal bridge, hypertelorism, long philtrum, open mouth, and hypoplastic teeth. 
CASE 2

This male infant was delivered spontaneously at term in vertex presentation, with a birth weight of $3200 \mathrm{~g}$, length $52 \mathrm{~cm}$, and head circumference $35 \mathrm{~cm}$. Apgar scores were 9 and 10 at one and five minutes, respectively. During the first 24 hours he had one episode of cyanosis following feeding. Chest radiographs and laboratory studies including spinal fluid examination were normal. He was treated with antibiotics for three days. On the fourth day total bilurubin went up to $13 \mathrm{mg} / \mathrm{dl}$, but started to normalise without intervention. $\mathrm{He}$ was discharged from the nursery five days after birth.

Evaluation at 5 months at another hospital showed an infant with severe hypotonia, poor head control, left torticollis secondary to sternocleidomastoid contracture, a cystic haemangioma behind the left ear fold, and minimal facial asymmetry. Although his physical growth appeared normal, significant delays in most areas of development were recognised by the age of 9 months, at which time he was assessed to be functioning at a 3 month level. He suffered several episodes of upper respiratory tract infections associated with otitis media and chronic constipation from very early infancy.

At 15 months of age he appeared alert, lying in a frog leg position. He responded to his mother, smiling at her voice, made good eye contact, but did not have purposeful reach and grasp. Visual tracking was inconsistent, an occasional horizontal nystagmus was noted, and funduscopic examination was normal. Head control was very poor and the neck was tilted to the left side. He was not able to turn from side to side or sit without support. His length was $79 \mathrm{~cm}$ (50th centile), weight $11 \cdot 1 \mathrm{~kg}$ (50th centile), OFC $48.5 \mathrm{~cm}$ ( 75 th centile), and IPD $5 \mathrm{~cm}$ (95th centile). The left side of the head and face was flatter than the right side. The fontanelles had closed. The ears were normal in size; a cystic haemangioma (one $\mathrm{cm}$ in diameter) was present on the posterior part of the left auricle. He had an open mouth, narrow, high arched palate, prominent nasal root, normal teeth, and tongue without fasciculations or atrophy (fig 2). The heart and lungs were normal and the abdomen was dis-

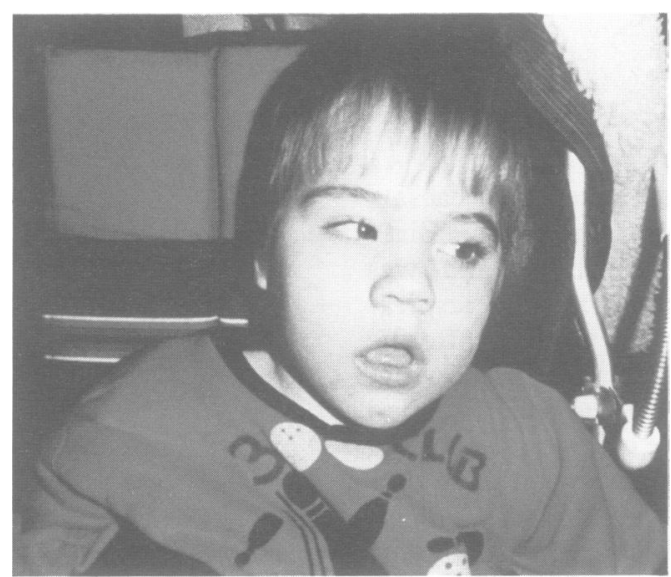

Figure 2 Case 2: broad nasal bridge, hypertelorism, long philtrum, and open mouth. tended with palpable faecal masses. A moderate degree of diastasis recti was present. The muscle weakness was severe and generalised. All deep tendon reflexes were absent, and plantars were decreased bilaterally. Moro and tonic neck reflexes had disappeared. The spine and genitalia appeared normal and the patellae were small. The left fifth finger showed clinodactyly, and palmar and digital creases were normal. He had his first grand mal seizure at the age of 3 years. At $3 \frac{1}{2}$ years of age there was no significant improvement in his muscle weakness, although he was beginning to sit with support. His speech was limited to one word.

\section{CASE 3}

This patient was the product of a first pregnancy, delivered at term spontaneously after prolonged labour, weighing $3700 \mathrm{~g}$. Floppiness was recognised very early and although his physical growth appeared normal, concerns were raised about delays in attaining milestones. He was beginning to sit with support at $2 \frac{1}{2}$ years of age and his vocabulary consisted of four words. His first episode of asthma occurred at 8 months and the first grand mal seizure at $2 \frac{1}{2}$ years. He was frequently constipated.

At 3 years of age his weight was $18.8 \mathrm{~kg}$ ( $>95$ th centile), length $99 \mathrm{~cm}$ (80th centile), OFC $51 \mathrm{~cm}$ (60th centile), ear length $6 \mathrm{~cm}$ (97th centile), and IPD $5.5 \mathrm{~cm}$ (97th centile). $\mathrm{He}$ was alert and could sit with minimum support (fig 3). His cry was feeble even to painful stimuli. His head was symmetrical and the fontanelles were closed. The nasal root was prominent. Examination of the eyes including funduscopy was normal. He drooled through

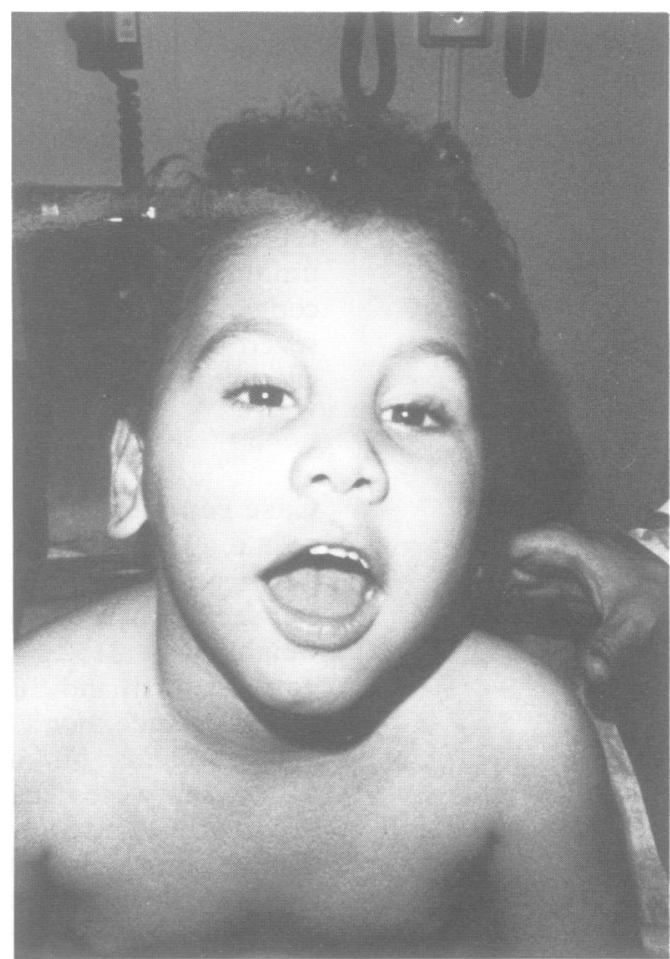

Figure 3 Case 3: prominent nasal root and open mouth. 
his open mouth, and his tongue showed no fasciculations or atrophy. He had normal teeth and his palate was narrow and highly arched. The liver edge was palpable $2 \mathrm{~cm}$ below the right costal margin through the distended abdomen. The penis and scrotum were normal, but the left testis was undescended. The muscle weakness was severe and generalised, with hypoactive deep tendon reflexes. The spine and patellae were normal. The distal phalanges of the thumbs were narrow. The fifth toes had hypoplastic nails. Plantar and palmar creases were normal.

\section{Family and pregnancy history}

The parents of the three patients were white Puerto Ricans, healthy and unrelated. The mother of case 2 was exposed to dental $x$ rays during the first trimester, and during the third trimester she was treated with antibiotics for urinary tract infection. His 14 year old sister has juvenile diabetes. No exposure to teratogens or medication before or during gestation was reported by the other two families. An older sister of case 1 died within 24 hours after birth from respiratory problems. She had "a big head and bent feet". None of the mothers had experienced decreased fetal activity. This may be because of problems of recall or communication, although one mother was primiparous.

\section{Dermatoglyphics}

The dermal patterns on the palms and fingers were unusual in all three patients. There was a preponderance of simple arch patterns; 12 of $30(40 \%)$ fingertip patterns were arches. The total finger ridge count was considerably decreased. All patients had simple arch patterns on the thumb tips.

\section{Radiological findings}

Pre- and postcontrast CT scans of the brain were normal in cases 1 and 3. Case 2 had a larger than usual fourth ventricle in the midline position, without evidence of a mass. Mild dilatation of the third and lateral ventricles was noted and the cortical sulci appeared enlarged. Radiographs of the chest, hips, and spine were normal in two patients. Case 1 had mild thoracolumbar scoliosis, pectus excavatum, and focal atelectasis in the base of the right lung.

There was a striking inconsistency in the ossification of the phalangeal and metacarpal epiphyses and that of the carpal bones. No carpal centres had appeared in two patients, while in case 2 a small centre of ossification was visible in the capitate (fig 4). Centres of ossification were not visible in the heads of the metacarpals and the distal ends of the radius. In contrast, ossification of the phalangeal epiphyses had begun, albeit delayed. At the age of 3 years, the bone age was interpreted as 18 months in all patients based on the ossification of the proximal and middle phalangeal centres.

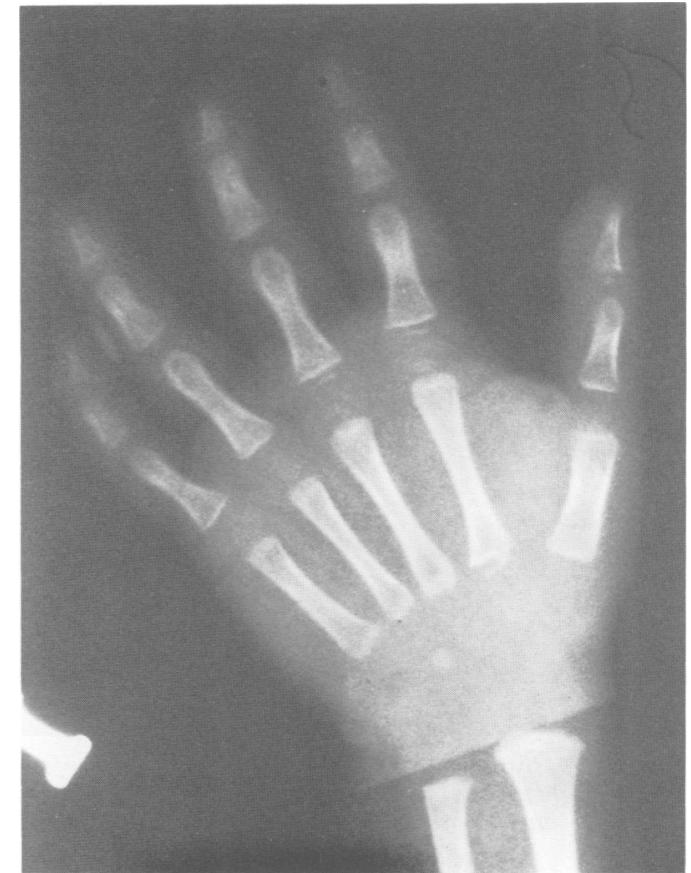

Figure 4 Radiograph of the wrist and hand of case 2 taken at the age of 2 years 6 months. Bone age 1 year 6 months. A small ossification centre of the capitate can be seen.

\section{Laboratory data}

A mild rise in aspartate aminotransferase ranging from 48 to 78 units/l was noted in all patients. Alanine aminotransferase was raised in case 1 (45 units/l), and lactic dehydrogenase was mildly raised in cases 2 and 3 . The remainder of the serum chemistries, creatine kinase, and thyroid hormones were within normal limits. Screening of urine and plasma for amino acids, organic acids, and mucopolysaccharides was normal. $\mathrm{G}$ banded karyotypes of peripheral blood showed normal chromosome constitutions.

Sleep and awake electroencephalograph (EEG) of case 1 showed an abnormal record suggesting an epileptiform activity although he never had any seizures. EEG tracings in two other patients with seizures were also abnormal showing epileptogenic T4 and P4 spikes. There was no evidence of neuropathy or myopathy in the electromyelographic (EMG) studies.

Open biopsies from patients were obtained from the vastus lateralis muscle under local anaesthesia. Significant abnormalities in muscle biopsies pertained to the relative number and size of the histochemical muscle fibre types shown by treatment with nicotinic acid dinucleotide tetrazolium reductase, non-specific esterase, and adenosine triphosphatase at $\mathrm{pH} 9.4$ and with preincubation at $\mathrm{pH} 4.4 .{ }^{2}$ In cases 2 and 3 type 1 fibres comprised 23.6 and $21 \cdot 2 \%$, respectively, while type 2 ( $2 \mathrm{~A}$ and $2 \mathrm{~B}$ together) fibres accounted for 76.4 and $78.9 \%$, respectively. The average diameter of the type 1 fibres in cases 2 and 3 was $17 \mu$ and $24 \mu$, respectively, while that of type 2 fibres was $21 \mu$ and $29 \mu$, respectively. Thus, type 2 fibres were $19 \%$ and $17 \cdot 2 \%$ larger in size than type 1 fibres (fig 5A, B). Histochemical examination of biopsied muscle of case 1 showed severe 

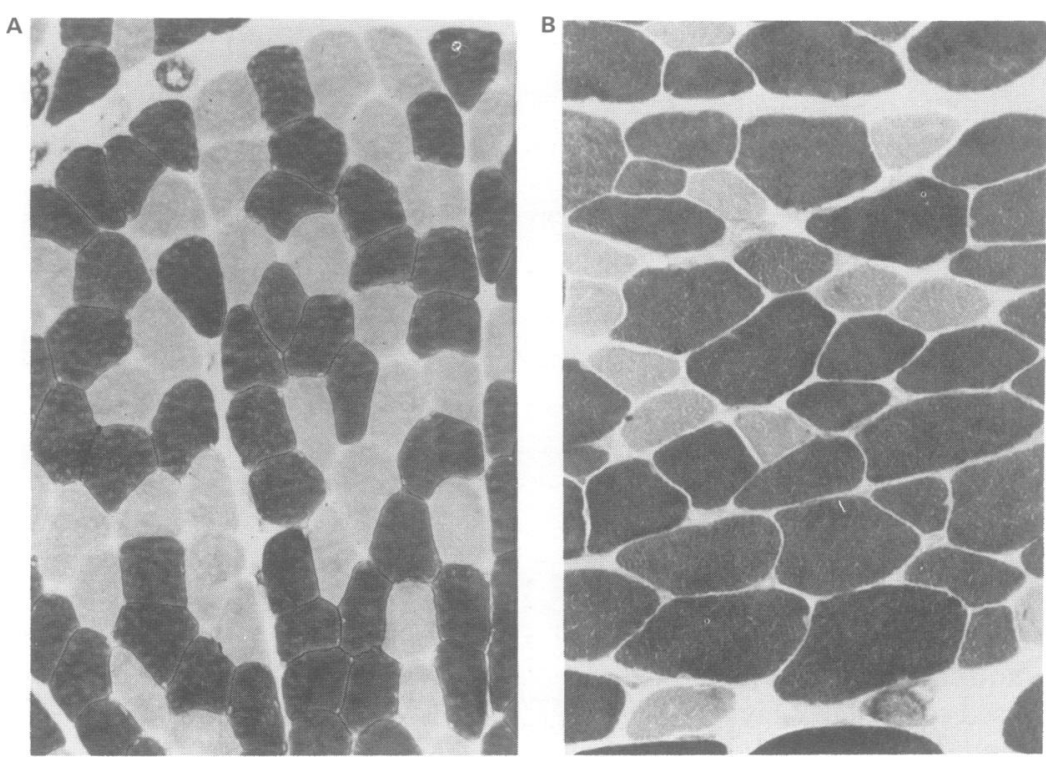

Figure 5 Histochemical fibre types. ( $A$ ) Normal infant: equal proportion and size of type 1 (light) and type 2 (dark) fibres. (B) Case 2: preponderance and large size of type 2 (dark) fibres.

Clinical and laboratory findings

\begin{tabular}{|c|c|c|c|}
\hline & Patient 1 & Patient 2 & Patient 3 \\
\hline $\begin{array}{l}\text { Age at evaluation } \\
\text { History }\end{array}$ & $4 \mathrm{y}$ & $3.5 y$ & $3 y$ \\
\hline Difficult labour & - & + & + \\
\hline Birth weight (g) & 3150 & 3690 & 3380 \\
\hline $\begin{array}{l}\text { Hypotonia } \\
\text { Milestones }\end{array}$ & & $\stackrel{+}{+}$ & $\stackrel{+}{+}$ \\
\hline Milestones & Delayed & Delayed & Delayed \\
\hline $\begin{array}{l}\text { Retardation } \\
\text { Seizure onset }\end{array}$ & Severe & Severe & Severe \\
\hline $\begin{array}{l}\text { Seizure onset } \\
\text { Frequent infections }\end{array}$ & $\vec{t}$ & $3 \mathbf{y}$ & $2 \mathrm{y}$ \\
\hline $\begin{array}{l}\text { Frequent infections } \\
\text { Constipation }\end{array}$ & $\begin{array}{l}+ \\
+\end{array}$ & - & + \\
\hline \multicolumn{4}{|l|}{$\begin{array}{l}\text { Constipation } \\
\text { Physical findings }\end{array}$} \\
\hline Length (centile) & 20 & 25 & 80 \\
\hline Weight (centile) & 90 & 50 & $>95$ \\
\hline OFC (centile) & 50 & 50 & 60 \\
\hline Open mouth, drooling & + & + & + \\
\hline Long philtrum & + & + & + \\
\hline High arched palate & + & + & + \\
\hline Prominent nasal root & + & + & + \\
\hline Distended abdomen & + & + & + \\
\hline Cryptorchidism & + & + & - \\
\hline Hypertelorism & + & + & + \\
\hline Tapered fingers & + & - & + \\
\hline Strabismus & + & - & - \\
\hline Pectus excavatum & + & - & - \\
\hline Torticollis & - & + & - \\
\hline Cystic haemangioma & - & + & - \\
\hline Hypoplastic teeth & + & - & - \\
\hline Crowding of toes & - & - & + \\
\hline Hypoplastic nails & - & 5th toes & - \\
\hline $\begin{array}{l}\text { Investigations } \\
\text { EEG }\end{array}$ & Abnormal & Abnormal & Abnormal \\
\hline Brain CT scan & Normal & Normal & Abnormal \\
\hline Electromyogram & Normal & Normal & Normal \\
\hline \multicolumn{4}{|l|}{ Muscle fibre types } \\
\hline Type 1 & Lower \% & $23 \cdot 6 \%$ & $21 \cdot 2 \%$ \\
\hline Type $2 A+2 B$ & Higher \% & $76 \cdot 4 \%$ & $78 \cdot 8 \%$ \\
\hline Diameter type 1 & Not done & $17 \mu$ & $24 \mu$ \\
\hline Diameter type 2 & Not done & $21 \mu$ & $29 \mu$ \\
\hline Creatine kinase & Normal & Normal & Normal \\
\hline Thyroid studies & Normal & Normal & Normal \\
\hline Bone age & Delayed & Delayed & Delayed \\
\hline Carpal centres & Absent & Capitate & Absent \\
\hline
\end{tabular}

paucity of type 1 fibres; however, more detailed measurements of fibre size were not performed.

\section{Discussion}

The growth and developmental pattern, and clinical, histochemical and radiological findings in these three unrelated white Puerto Rican boys are strikingly similar (table). All had congenital non-progressive and generalised hypotonia, severe psychomotor retardation, chronic constipation, seizures or abnormal EEG tracings or both, abnormal dermatoglyphics, delayed and dysharmonic skeletal maturation, a paucity and small size of fibre type 1 , and preponderance and larger size of fibre type 2 in skeletal muscle. All had a distended abdomen, hypertelorism, long philtrum, narrow, highly arched palate, prominent nasal root, and drooling from an open mouth. In addition, two of three boys had cryptorchidism, tapering fingers, and recurrent upper and lower respiratory tract infections. A number of other features such as cystic haemangioma on an ear lobe, crowding of toes, and unilateral facial hypoplasia were noted in individual patients. Rises in liver chemistries were mild and inconsistent. Growth parameters and head size were within normal centiles for all patients; one patient was overweight.

The term "dysharmonic" skeletal maturation was applied by Poznansky et $a l^{3}$ to describe differences in the degree of ossification between the carpals, metacarpals, and phalanges. Ossification of the carpal bones, as a group, is much more variable than in the phalangeal and metacarpal epiphyses in response to various stimuli that advance or retard the bone age ${ }^{4}$; the carpals are more likely to be ahead of the tubular bones when the maturation is advanced, while the opposite is true when the maturation is retarded. The latter seems to be the case in our patients where the phalangeal age is delayed, whereas the ossification of the carpal bones has not even begun between $2 \frac{1}{2}$ and $3 \frac{1}{2}$ years. The delayed bone age despite good physical growth and dysharmony of skeletal maturation are impressive findings in all patients.

Histochemical studies of biopsied muscle showed a paucity of type 1 and predominance of type 2 muscle fibres in all patients, and in cases 2 and 3 the diameter of type 2 fibres was larger than the type 1 fibres by a margin greater than $12 \%$, referred to as congenital fibre type disproportion (CFTD). ${ }^{5}$ Brooke $^{5}$ used the term CFTD to describe a group of 12 (five male and seven female) infants with profound hypotonia, decreased height and weight, contractures, kyphoscoliosis, high arched palate, and congenital hip dislocation. However, subsequent observations of CFTD in patients with a variety of well delineated entities such as fascioscapulohumeral dystrophy, fetal alcohol syndrome, globoid cell leucodystrophy, Pompe's disease, rigid spine syndrome, centronuclear myopathy, nemaline myopathy, and myotonic dystrophy led some authorities to consider that CFTD is a nonspecific finding and not a unique clinicopathological entity. ${ }^{6}$ Hypotonia in our patients appears to be of central origin and can be attributed to a primary central nervous system (CNS) defect. Delayed psychomotor development, absent speech, abnormal EEG, and seizure disorder also reflect disorganised CNS function. However, the observed weakness of muscles along with histochemical evidence of CFTD suggest the possibility of a genuine myopathic component. 
The patients presented here bear some resemblance to patients with Borjeson-Forssman-Lehmann syndrome, ${ }^{78} \mathrm{FG}$ syndrome, ${ }^{910}$ Zellweger syndrome, ${ }^{112}$ Prader-Willi syndrome, ${ }^{1314}$ Coffin-Lowry syndrome, ${ }^{1516}$ and X linked mental retardation associated with $\alpha$ thalassaemia. ${ }^{17}{ }^{18}$ Although they share features such as hypotonia, mental retardation, chronic constipation, abnormal EEG, seizures, cryptorchidism, and tapering fingers, there are wide areas of differences. In the first place our patients do not have the clinical, radiological, haematological, biochemical, or cytogenetic abnormalities which are specific to these syndromes. Moreover, they are set apart from other entities by characteristics such as normal physical growth and head size, delayed bone age despite normal physical growth, dysharmonic skeletal maturation, increased frequency of simple arch patterns on the fingertips, and CFTD. Although dysharmonic skeletal maturation, and CFTD are generally considered non-specific findings, their presence in the patients reported here indicates a stereotype that should provide important objective clues for identifying similar patients.

The aetiology of the syndrome described here remains to be determined. None of the families had more than one patient. Absence of consanguinity, occurrence in sibs, and partial expression in any members of the families need not exclude an autosomal recessive mode of inheritance. An X linked mode of inheritance appears likely because the condition so far has been seen only in boys. However, these are only a few observations, and further case reports are needed to advance the precise mode of inheritance. It is worth noting that all the patients were white Puerto Ricans. A search among hypotonic infants of Puerto Rican/ Hispanic origin is likely to uncover similar cases which can be readily ascertained apply- ing the clinical, radiological, and histochemical criteria.

1 Dubowitz V. The floppy infant. Clinics in developmental medicine. No 76. 2nd ed. Philadelphia, J B Lippincott, 1980.

2 Dubowitz V, Sewry CA, Fitzsimons RB. Muscle biopsy: a practical approach. 2nd ed. Philadelphia: Bailliere Tindall, 1985:28-40,56-67.

3 Poznansky AK, Garn SM, Kuhns LR, Sandusky ST. Dysharmonic maturation of the hand in congenital malformation syndromes. Am $\mathcal{F}$ Phys Anthropol 1971;35:41732 .

4 Poznansky AK. The hand in radiologic diagnosis with gamuts and pattern profiles. Philadelphia: Saunders, 1984:67-96.

5 Brooke MH. Congenital fiber type disproportion. In: Kakulas BA, ed. Clinical studies in myology. Amsterdam: 1973:147-59.

Banker BQ. Congenital fiber type disproportion. In: Engel AG, Banker BQ, eds. Myology. Vol 2. New York: McGraw-Hill, 1986:1532-3.

7 Borjeson M, Forssman H, Lehmann O. An X-linked, recessively inherited syndrome characterized by grave mental deficiency, epilepsy, and endocrine disorder. Acta Med Scand 1962;171:12-21.

8 Ardinger HH, Hanson JW, Zellweger HU. Borjeson-Forssman-Lehmann syndrome. Further delineation in five cases. Am ₹ Med Genet 1984; 19:653-64.

9 Opitz JM, Kaveggia EG. The FG syndrome: an X-linked recessive syndrome of multiple congenital anomalies and mental retardation. $Z$ Kinderheilkd 1974;117:1-18.

10 Opitz JM, Kaveggia EG, Adkins WN Jr, et al. Studies of malformation syndromes of humans XXXIIIC. The FG syndrome - further studies on three affected individuals from the FG family. Am $\mathcal{F}$ Med Genet 1982;12:147-54.

11 Kelley RI. The cerebrohepatorenal syndrome of Zellweger. Morphologic and metabolic aspects. Am $f$ Med Genet 1983;16:503-17.

12 Wilson GN, Holmer RG, Custer J, et al. Zellweger syndrome: diagnostic assays, syndrome delineation, and potential therapy. Am f Med Genet 1986;24:69-82.

13 Prader A, Labhart A, Willi H. Ein Syndrom von Adipositas, Kleinwuchs, Kryptorchismus und Oligophrenie nach Myatonieartigem Zustand im Neugeborenealter. Schweiz Med Wochenschr 1956;86:1260-1.

14 Hall BD, Smith DW. Prader-Willi syndrome a resume of 32 cases including an instance of affected first cousins, one of whom is of normal stature and intelligence. $\mathcal{F}$ Pediatr whom is of normat

15 Young ID. The Coffin-Lowry syndrome. 7 Med Genet $1988 ; 25: 344-8$.

16 Vles JSH, Haspeslagh M, Raes MMR, Fryns JP, Casaer P, Eggermont E. Early clinical signs in Coffin-Lowry syndrome. Clin Genet 1984;26:448-52.

17 Weatherall DJ, Higgs DR, Bunch C, et al. Hemoglobin $\mathrm{H}$ disease and mental retardation: a new syndrome or a 8 remarkable coincidence? N Engl f Med 1981,305:607-12. Gibbons RJ, Wilkie AOM, Weatherall DJ, Higgs DR. A newly defined X linked mental retardation syndrome associated with alpha-thalassaemia. $f$ Med Genet
1991;28:729-33. 